\title{
Dual infection with Acinetobacter baumannii and Klebsiella pneumoniae in a patient with multiple comorbidities - case presentation
}

\author{
Oana Săndulescu ${ }^{1,2^{*}}$, Monica Andreea Stoica², loana Berciu ${ }^{1,2}$, Anca Streinu-Cercel ${ }^{1,2}$, Liliana Lucia Preoțescu ${ }^{1,2}$, \\ Adrian Streinu-Cercel ${ }^{1,2}$ \\ From The 10th Edition of the Scientific Days of the National Institute for Infectious Diseases "Prof Dr Matei \\ Bals" \\ Bucharest, Romania. 15-17 October 2014
}

\section{Background}

Bacterial coinfection is a rarely described phenomenon. We present a case of dual infection in a patient with multiple comorbidities and advanced immunesuppression.

\section{Case report}

A 35 year-old male patient presented to our clinic in May 2014 for progressive malaise, low-grade fever and nausea.

His medical history revealed chronic glomerulonephritis and renal failure with hemodialysis from 2005 to 2010; kidney transplant in 2010, with transplant rejection and positive CMV-IgM in March 2014. He also presented arterial hypertension, ischemic heart disease and left ventricular hypertrophy since 2010, multiple episodes of sepsis and pneumonia with Klebsiella spp. through digestive microbial translocation (colonic ulcerations), and a double aortocoronary bypass in March 2014. The thoracotomy incision had healed almost completely, but the right calf incision presented signs of infection.

His concomitant therapy included anti-hypertensive agents, antiplatelet therapy, ganciclovir, immune-suppression therapy with mycophenolic acid, and prednisone $(10 \mathrm{mg} /$ day $)$.

On admission, the clinical exam was normal, except for bilateral lower limb edema and inflammation of the right calf incision area, with multiple patches of exposed soft

\footnotetext{
* Correspondence: oanasandulescu1@gmail.com

${ }^{1}$ Carol Davila University of Medicine and Pharmacy, Bucharest, Romania
} Full list of author information is available at the end of the article tissue and suppuration. Biologically, he presented pancytopenia (WBC 2,100 cells $/ \mu \mathrm{L}$, hemoglobin $6.8 \mathrm{~g} / \mathrm{dL}$, thrombocytes 137,000 cells $/ \mu \mathrm{L}$ ), nitrogen retention syndrome (urea $147.4 \mathrm{mg} / \mathrm{dL}$, creatinine $4.4 \mathrm{mg} / \mathrm{dL}$ ). The patient's reactivity was quite low given the concomitant immune-suppressive treatment, with ESR $38 \mathrm{~mm} / 1 \mathrm{~h}$, fibrinogen $351 \mathrm{mg} / \mathrm{dL}$, and CRP $10 \mathrm{mg} / \mathrm{L}$.

Urine cultures, repeated blood cultures and procalcitonin were negative, but the smear from the right calf incision wound identified inflammatory cells and Gramnegative coccobacilli, and CLED cultures grew smooth, yellow, lactose-fermenting colonies. Microscan (Siemens, Munich, Germany) identified carbapenemase-producing Klebsiella pneumoniae (KPC) and the strain was subcultured and grew a smooth, grey, non-lactose-fermenting colony, identified on VITEK (bioMérieux, Paris, France) as Acinetobacter baumannii. Both strains were resistant to all tested drugs except for colistin and tigecycline. As both strains initially grew in a single isolated culture, with homogenous morphology, it took repeated cultures to separate the two strains. The patient's evolution was favorable under treatment with tigecycline and local instillations of colistin.

\section{Conclusion}

We have presented a case of coinfection with two extremely resistant Gram-negative strains in a patient with multiple comorbidities and limited treatment options. Interestingly, both strains grew entwined in a colony that presented a single morphology not suggestive for coinfection. Bacterial identification techniques allowed an etiologic diagnosis and targeted antimicrobial therapy. 


\section{Acknowledgements}

1) POSDRU/159/1.5/S/137390.

2) Carol Davila University of Medicine and Pharmacy, Young Researchers

Projects Grant Competition, contract number 28.336/04.11.2013.

\section{Authors' details}

'Carol Davila University of Medicine and Pharmacy, Bucharest, Romania.

${ }^{2}$ National Institute for Infectious Diseases "Prof. Dr. Matei Balş", Bucharest, Romania.

Published: 15 October 2014

doi:10.1186/1471-2334-14-S7-P26

Cite this article as: Săndulescu et al.: Dual infection with Acinetobacter baumannii and Klebsiella pneumoniae in a patient with multiple comorbidities - case presentation. BMC Infectious Diseases 2014 14(Suppl 7):P26.

Submit your next manuscript to BioMed Central and take full advantage of:

- Convenient online submission

- Thorough peer review

- No space constraints or color figure charges

- Immediate publication on acceptance

- Inclusion in PubMed, CAS, Scopus and Google Scholar

- Research which is freely available for redistribution

Submit your manuscript at www.biomedcentral.com/submit
C Biomed Central 